After the end of January these same sheep had their daily quota of light reduced gradually from twenty-one hours to just under fourteen hours by March 21. Thereafter, this reduction was maintained by enclosing them in a blacked-out pen at appropriate times each day, until by the third week of June they were receiving daily only $5 \frac{1}{2}$ hours of light. The sheep in this group commenced breeding on May 20, and within twenty-two days all were in full breeding state, including those which had lambed only ten weeks previously. Those ewes running with the vasectomized rams are now (July 1947) returning for service every 16-17 days, while those which have been served by a fertile ram appear to have settled to a pregnancy normal in every way except the time of year of its commencement.

A further group of ewes was introduced into the experiment on March 23. They had been under the influence of the naturally lengthening days from late December to late March, at which time they joined the other experimental group of sheep. They had thus reached a quota of nearly fourteen hours of light per day, when they were submitted to a gradual decrease. This group of ewes commenced breeding on June 28, again 10-14 weeks after their longest day.

From these results it appears evident that: (a) Seasonal variation in length of day is the ehief factor determining the time of onset and the duration of the natural breeding season in sheep. (b) This natural breeding season can be modified and even reversed at will by altering artificially the length of day. (c) A change from increasing length of day to decreasing length of day induces reproductive activity, the breeding response occurring 10-14 weeks after the change. (d) A change from decreasing length of day to increasing length of day induces ancstrum 10-14 weeks after the change. (e) A change from decreasing length of day to increasing length of day is apparently just as effective at a level of $12 \frac{1}{2}$ hours as it is at a level of nine hours in inducing anœestrum. Similarly, a change from increasing length of day to decreasing length of day is apparently just as effective at a level of $13 \frac{1}{2}$ hours as it is at a level of twentyone hours in inducing reproductive activity.

This work, which is still in progress, is being carried out while holding a Walter and Eliza Hall Travelling Scholarship from the University of Queensland. Detailed results of the work will be published elsewhere at a later date. Sincere thanks are tendered to Dr. John Hammond for his encouragement and advice.

School of Agriculture,

N. T. M. Yeates

Cambridge.

July 11 .

${ }^{1}$ Bissonnette, T. H., I'roc. Roy. Soc., B, 110, 322 (1932).

2 Hill, M., and Parkes, A. S., Proc. Roy. Soc., B, 113, 537 (1933).

'Marshall, F. H. A., Proc. Roy. Soc., B, 122, 413 (1937).

- Hammond, J., jun., J. Agric. Sci., 34, 97 (1944).

'Bissonnette, '1. H., Phys. Zool., 14, 379 (1941).

\section{Ascorbic Acid Content of Whale's Milk}

DURING whaling operations in the Antarctic, opportunity arose to carry out an ascorbic acid estimation on a fairly fresh sample of whale milk. The sample, about 200 c.c., was drawn from the main duct of one of the mammary glands of a lactating fin whale (Baloeonoptera physalus) which had been dead not more than six hours. Fresh whales are not common on a factory, and lactating whales are pro- tected, so that the occurrence of a fairly fresh lactating whale is comparatively rare.

Ascorbic acid was estimated on the filtrate from trichloracetic acid precipitation of the milk, using 2: 6 dichlorophenol indophenol as indicator. Results gave an ascorbic acid content of about $7 \mathrm{mgm} . / 100 \mathrm{ml}$. for the original sample. (Figures for human milk are 4-8 mgm. $/ 100 \mathrm{ml}$. and for cow milk around 1-4 mgm./100 ml.) Unfortunately, it was not possible to estimate the vitamin $\mathrm{C}$ present in the krill on which the whale feeds.

My thanks are due to "Discovery" Investigations for the opportunity of going south, and to United Whalers, Ltd., for their hospitality.

Natural History Department,

Marischal College, Aberdeen. July 24.

\section{Further Remains of the Sterkfontein Ape-man, Plesianthropus}

Ax the beginning of April we restarted work at Sterkfontein in the search for more remains of Plesianthropus; and we were successful in getting remains of a number of individuals and a perfect skull of an elderly female, of which an announcement was made in Nature of May 17. Unfortunately, owing to a difference of opinion with the Historical Monuments Commission, further work was delayed for a month.

On June 24 we discovered the nearly complete and fairly well preserved lower jaw of a large middleaged male. With it were found part of a maxilla and much of a humerus and scapula. The humerus has the head perfect, and most of the shaft is also present but badly crushed. The distal end is lost. The head of the humerus is practically human in size and structure. The scapula has the glenoid portion and the coracoid satisfactorily preserved with much of the spine. The scapula is not quite human, but neither is it anthropoid.

On August 1 we discovered part of a skeleton with a perfect pelvis, much of a femur, a tibia, some ribs and vertebræ, and parts of the skull very badly crushed and broken. The skeleton seems to be that of a female.

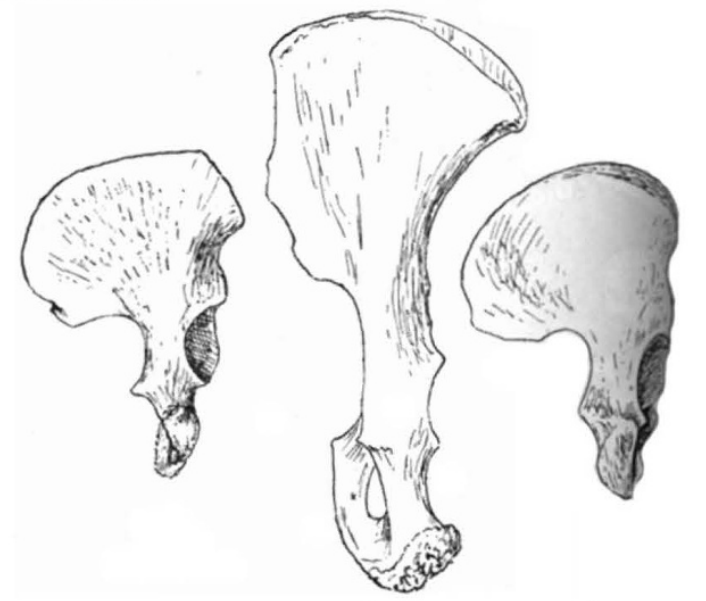

A

$$
B
$$

$C$

A. Right side of pelvis of Plesianthropus transvaalensis Broom.

B. " " " " " $\quad$ male Bushman

All $\frac{1}{5}$ natural size. 